\title{
Learning under Uncertainty: A Grounded Theory Study
}

\author{
Eurico Lopes \\ Escola Superior Tecnologia, Computer Engineering Department, Av. Empresario, \\ 6000-767 Castelo Branco, Portugal \\ eurico@ipcb.pt
}

\begin{abstract}
This paper discusses learning under uncertainty; starting from a vision of how to support systems working within information systems, helping decision-making under uncertainty. The first results show the concept of learning under uncertainty. Then a change for a qualitative research approach was taken using Grounded Theory Methodology. The results are presented in a framework that represents a basic theory of learning under uncertainty process. This framework presents learning under uncertainty throw a tacit and operational learner capacities and a cognitive and impact on the learner. It also shows how uncertainty is sensed in order to start the learning process. Learning under uncertainty could be summarized through the use of a human approach, dialogue and interaction within social-actors in the uncertain context.
\end{abstract}

Keywords: Grounded Theory, Learning under Uncertainty, Constructivism, System Thinking, Information Systems Modelling.

\section{Introduction}

Initially the researcher was interested in understanding how decision support systems worked around information systems, supporting decision-making (D-M) under uncertainty. As the research continued, the researcher decided to merge other concepts found in literature such as systems thinking and complexity. At this stage, some research questions were asked and interviews were made. Then, when trying to find the answers to those questions, the researcher obtained, a commonality that unites all the related experiences; every one seemed to be embedded in a learning experience that upholds a learning concept under uncertainty. So, the necessity to discard the initial methodology was evident and a new one, Grounded Theory Methodology (GTM), was considered to suit the research purpose. Furthermore this paper will show grounded characteristics of learning under uncertainty from a qualitative research approach. Finally, a framework will be presented to explain the learning under uncertainty process.

This paper shows an introductory research inspecting how information systems and complexity guide D-M under uncertainty. The outcome is learning under uncertainty. Following an overview of learning under uncertainty in specific fields where uncertainty has been addressed in the context of learning. The choice of a qualitative approach and the use of GTM are justified. Finally the discussion of the results and a framework are presented. 


\subsection{Preliminary Research}

To begin with, the researcher was inspecting how decision-makers under uncertainty and complexity build a model, an external and explicit representation of part of the reality seen by the decision-maker. By answering this question, was researched the way decision-makers comprehend the uncertain context. The researcher's hypothesis are based in the computer system engineering field [1], [2], [3] and reinforced by an initial literature review on prescriptive decision-making [4], [5], [6], [7] descriptive decision-making [8], [9], [10] systems thinking world [11], [12], [13], [14], [15] and complexity theory [16], [17], [18], [19].

The researcher was expecting answers that supported a calculated way of thinking or risk evaluation technique. At this stage, some research questions were designed and interviews were made to a set of heterogeneous participants in the business and management field, from small to global organizations. Following an open-interview format, no direct questions were asked, giving the interviewees the possibility to speak freely whilst revealing their feelings about their experience. In this way, the interviewees' accounts are subject to the reconstruction, without any preconceived questionnaire or other research strategy. After each interview, the researcher perceived that each interviewee did not relate any objectively observed natural world, he did not recount any formulated hypothesis that he had previously tested against, obtained quantified data. Each interviewee revealed how he became involved in a social interaction and what were they perceived for.

\subsection{Learning Focus}

The task to find answers was then a work of serendipity from the interviews, data, readings and a recurring return to the interviews.

From these experiences the researcher interpreted and constructed meanings that sustain a central concept of learning under the uncertain and complex context. This interpretation was not something that is there, waiting to be observed and measured. That reality was hidden and has to be constructed in order to have existence, it is not something that is offered as material substance or has been asked for. There now follows the first interpretations, impressions that the researcher sensed that uphold this learning concept.

\subsection{Focalizing}

From the first impressions and analysis of the first interview, modelling techniques from the system thinking world [14] were not used, not because they weren't asked, but because they did not keep the interviewee's D-M process going. This fact was not present, even if attempting to link with Strategic Management [17], [20], [21] or other techniques. The link does not work and the recounted experiences did not fit, sustained hypotheses were empty, and nothing made sense at this first analysis.

Furthermore, in the second analysis work over the second interview, the analysis gave the researcher a new horizon. Modelling techniques [2], [3] and risk evaluation [5], [22] were not the decision-maker support. The interviewee knew risk evaluation and game theory, however, as he argued, these techniques were not the substance that guided D-M under-uncertainty. It was not a question of risk evaluation or the use of 
supportive tools. At that time, the researcher perceived from the second interview that learning is indirect; it is a process that, from the interviewee's words provided meaning around the central concept of Learning.

The researcher did a third interview and the results of this interview did not give a new insight for the research. The researcher based their assumptions on suggested theories by the interviewee and he supposed that they could fit with the recounted experiences. The results were that the concept of learning stated by the interviewee guided D-M: "I think there are connections between the way people learn and the way they take decisions under uncertainty". However the idea that learning is a process under D-M under uncertainty and complexity was not clearly sustained by a common literature found in the field.

The central idea from the fourth interview was the need to learn having confidence to solve problems, to create a social relationship with professional colleagues based in daily meetings and be supported by the use of information and communications technology. A central idea of learning to decide fast and later adjust decisions if necessary also evolved.

Table 1. Analysis summary of initial research questions

\begin{tabular}{|c|c|c|c|c|}
\hline \multicolumn{5}{|c|}{$\begin{array}{l}\text { Initial research questions } \\
\text { Are decision-maker's }\end{array}$} \\
\hline Interview & using complexity theory? & $\begin{array}{l}\text { making some sort of risk } \\
\text { evaluation? }\end{array}$ & $\begin{array}{l}\text { using Decision Support } \\
\text { Systems or other tools to } \\
\text { help? }\end{array}$ & $\begin{array}{l}\text { Sensed, Interpreted and } \\
\text { Constructed Meaning }\end{array}$ \\
\hline 1 & No & No & $\begin{array}{l}\text { Yes, but he does not } \\
\text { understand them "It is that I } \\
\text { do not perceive anything of } \\
\text { that. There are things I do } \\
\text { not know that they had } \\
\text { become there." }\end{array}$ & $\begin{array}{l}\text { Decisions under } \\
\text { uncertainty are not } \\
\text { found in this premises, } \\
\text { in information systems }\end{array}$ \\
\hline 2 & $\begin{array}{l}\text { No, but he believes in natural } \\
\text { evolution }\end{array}$ & $\begin{array}{l}\text { Yes, but it has no impact how } \\
\text { he decides, in his words }\end{array}$ & $\begin{array}{l}\text { Yes, scenarios and game } \\
\text { theory, but he does not feel } \\
\text { confident with them, it his a } \\
\text { personal position, assuming } \\
\text { risk }\end{array}$ & $\begin{array}{l}\text { Decisions under } \\
\text { uncertainty depend on } \\
\text { the personal confidence } \\
\text { and risk taking } \\
\text { behaviour and not in } \\
\text { alternative tools } \\
\end{array}$ \\
\hline 3 & $\begin{array}{l}\text { No, but organization history } \\
\text { and values are important }\end{array}$ & $\begin{array}{l}\text { Yes, some statistics, but in } \\
\text { his words they do not count }\end{array}$ & $\begin{array}{l}\text { Yes, managerial and } \\
\text { statistical packages which } \\
\text { does not account for a } \\
\text { decision under uncertainty. } \\
\text { "It is not a financial model } \\
\text { with lot of consultants, } \\
\text { statistics and so on... it is } \\
\text { much more about living the } \\
\text { values" }\end{array}$ & $\begin{array}{l}\text { Decisions under } \\
\text { uncertainty are more } \\
\text { about the living values } \\
\text { of the decision-maker. }\end{array}$ \\
\hline 4 & $\begin{array}{l}\text { No. "I don't see how } \\
\text { complexity theory helps" }\end{array}$ & $\begin{array}{l}\text { No. "...managers don't } \\
\text { reduce uncertainty } \\
\text { objectively... they reduce the } \\
\text { perception of uncertainty". }\end{array}$ & No & $\begin{array}{l}\text { Decisions under } \\
\text { uncertainty are a } \\
\text { question of how a } \\
\text { personal manager } \\
\text { reduces the perception } \\
\text { of uncertainty } \\
\end{array}$ \\
\hline 5 & No & $\begin{array}{l}\text { Yes, but not a way to reduce } \\
\text { uncertainty. Decisions must } \\
\text { be prompt in great } \\
\text { uncertainty context, no time } \\
\text { for reducing uncertainty }\end{array}$ & $\begin{array}{l}\text { Yes, mainly to support } \\
\text { organizational } \\
\text { communications between } \\
\text { bankers and the market and } \\
\text { as a living report from } \\
\text { successful and failed cases }\end{array}$ & $\begin{array}{l}\text { Decisions under } \\
\text { uncertainty must be } \\
\text { prompted and not much } \\
\text { time to reduce } \\
\text { uncertainty }\end{array}$ \\
\hline
\end{tabular}

The fifth interview also offered fundamental ideas around the learning concept and a need for a social network which becomes more consistent. In the interviewee's words "opposition or disagreement is not a bad thing, it is good, it is learning", "I think too many managers spend time with computers and charts... it is much more about living the values, expressing the spirit of what should be", "I don't think I need a huge amount of statistical modelling to reach a decision, because often a decision is 
all about the human interaction". This is also a rejection of the initial thoughts, from where systems and modelling strategies should be important. Table 1 shows a summary analysis of how the researcher interpreted and made a construction of meaning from the interviewees' accounted experiences and table 2 presents sample phrases from each interview and it created a meaning. So, it became clear in the researcher's mind, that decisions under uncertainty depend on risk taking behaviour or are more about the living values of the decision-maker and how we learns under uncertainty.

Then another problem materialised - the literature does not make references to this learning process, and even fewer references exist of Learning under Uncertainty.

Table 2. Sample phrases from each interview and created meaning

\begin{tabular}{|c|c|c|}
\hline Interview & Extracts Interview & $\begin{array}{c}\text { Sensed, Interpreted and Constructed } \\
\text { Meaning }\end{array}$ \\
\hline 01 & $\begin{array}{l}\text { "People know that the direction is for there, but not the way! Let us say that the way } \\
\text { become walking, experience." } \\
\text { "The reactivity of whom is in this process all has to be very great; therefore if people will not } \\
\text { have capacity to answer to the necessities, in this case of the customers, but sometimes } \\
\text { this can not be only customers... It can be fans, can be the proper family, it can be } \\
\text { whatsoever, depending the type of organization, what we need is find out to react" }\end{array}$ & $\begin{array}{l}\text { Learn with experience } \\
\text { Sense other needs, and Learn to be } \\
\text { capable to answer them }\end{array}$ \\
\hline 02 & $\begin{array}{l}\text { "We at SONAE assume a risk taker position and when we have much uncertainty we go to } \\
\text { the challenge and when it arrives exactly at the dark room, where we become lost. Before } \\
\text { this, it goes trying... and the limit is basically to never back the company." }\end{array}$ & $\begin{array}{l}\text { Trying, going to the challenge and } \\
\text { learning how to became out } \\
\text { successfully }\end{array}$ \\
\hline 03 & $\begin{array}{l}\text { "We have to look at the history institution, personal dynamics, or students want to do" } \\
\text { "opposition or disagreement is not a bad thing, it is good, it is learning" }\end{array}$ & $\begin{array}{l}\text { Sense and learn the organization } \\
\text { history and values. Learn also with } \\
\text { disagreements }\end{array}$ \\
\hline 04 & $\begin{array}{l}\text { "I think there are connections between the way people learn and the way they take } \\
\text { decisions" } \\
\text { "...learning value decisions ..." }\end{array}$ & $\begin{array}{l}\text { Making decisions is a Learning } \\
\text { process }\end{array}$ \\
\hline 05 & $\begin{array}{l}\text { "Here we have to learn to decide extraordinarily fast and always under conditions of great } \\
\text { uncertainty. This is different from European organizations where we try first to reduce } \\
\text { uncertainty and then take a decision" }\end{array}$ & $\begin{array}{l}\text { Learn to observe and be prompted to } \\
\text { decide, not delaying reducing } \\
\text { uncertainty }\end{array}$ \\
\hline
\end{tabular}

\section{Learning Theories}

Learning theories are attempts to describe how people learn. From the literature there are three main learning paradigms: Behaviourism, Cognitivism, and Constructivism [23]:

- Behaviourism is an approach to psychology where learning is a result of conditioning behaviour. This behaviour may result either in reinforcement, which increases the likelihood of that behaviour occurring again; or punishment, which decreases the likelihood of the same behaviour recurring in the future. In behaviourism, "a learner is essentially passive, responding to environmental stimuli. The learner starts off as a clean slate (i.e. tabula rasa) and behaviour is shaped through positive reinforcement or negative reinforcement" [23].

- Cognitivism expands behaviourism accepting that mental states are appropriate to analyse and subject to examination to understand mental function. Humans are assumed to act on the basis of representations of their environment that are processed in their brains [24]. Learning is a process of developing more and more accurate representations of external, pre-given reality. 
"Cognitivism uses the metaphor of the mind as computer: information comes in, is processed, and leads to certain outcomes" [23].

- Constructivism views learning as a process in which the learner constructs or builds new ideas or concepts based upon current and past knowledge. Constructivist learning involves constructing one's own knowledge from one's own experiences [25]. This should be the most appropriate learning theory for the present research, since uncertainty is not known; this should be sensed and learned with the experience, since "Learners continuously test these hypotheses through social negotiation. Each person has a different interpretation and construction of knowledge process. The learner is not a blank slate (tabula rasa), but brings past experiences and cultural factors to a situation" [23]

The following is an overview of learning under uncertainty in a specific field where uncertainty has been addressed in the context of learning.

Bligh [26] states a constructivist position in teaching to know what to teach, but also to know what students know and think. He proposes an approach using uncertainty to guide students in thinking and behaving to produce medical decisions. Bligh proposes "expressing uncertainty is the best way of learning and teaching because it allows exploration of the cognitive processes involved in clinical decision making" [26:2]. This is related with how students (doctors in training) apply the information they obtain from clinical experience and investigations, to perform a diagnosis. Bligh states "Knowing more about what students are thinking when they are presenting a case to you, or about what they are thinking after a lecture will enable teachers to help their students learn better" [26:2].

Dayan and $\mathrm{Yu}$ [27] in their experiments with small rats have carried out research regarding learning and uncertainty from three perspectives: statistical theories, psychological models in which attention is paid to stimuli with an effect on the speed of learning associated with those stimuli, and neurobiological data on the influence of the neuromodulators on learning and inference. Their conclusions are - the more uncertain a stimulus, the faster the animal learns about that stimulus: "It is obvious that learning should be occasioned by unfamiliarity" [27:10]. This links with the research study, - that uncertain stimuli generate learning, which is found in the current research where an uncertain and unfamiliar, or unknown context will guide learner thorough a process of dealing with that uncertainty, in order to understand it. This unfamiliar context is an uncertain context in the sense that an individual (human) will have to 'familiarise' himself with it, reconstructing it with others (assuming that reality is social-constructed), in order to know it.

In the field of Economics, Arrow states "Learning is certainly one of the most important forms of behaviour under uncertainty" [28:13]. Arrow argues that each individual achieves his satisfaction level at minimum cost. "If we assume that individuals are averse to risk, individuals and firms in planning for an uncertain future may want to make sure that their demands and outputs are mutually compatible" [28:268]. Arrow writes about consumer behaviour and so this is a very specific form of decisions and sensing markets related to consumers.

So uncertainty introduces learning like the term 'surprisal' from Hayles [29]. Bryant [30] argues that when the 'surprisal' element in the information is known, then 
uncertainty is reduced e.g. the first time you tell something new there may be something surprising about it, and we learn under uncertainty. Bernstein considers that the existence of surprise shows that uncertainty is more likely than probability, "prevalence of surprise in the world of business is evidence that uncertainty is more likely to prevail than mathematical probability" [22:220-1].

All the subsequent research work drew on the premise of this focus, and tried to understand how it works, what processes are involved and properties surrounding them. This changes the research strategy for a qualitative approach, which follows a justification.

\section{Qualitative Approach Using GTM}

There is recognition, that qualitative research is essential to capture real-world answers to the real world problems in a way that is not possible in a quantitative context [31], [32]. Glaser and Strauss [33] focus on qualitative research, which is usually the most "adequate" and "efficient" way to achieve the nature of information required, and to contend with the difficulties of an empirical situation. Regardless of these strengths, qualitative research also shows some weakness, related with qualitative samples, and there is no systemic or statistical approach, usually working with small samples of people [34]. Eldabi et al [35] claims that qualitative approaches to research take a less planned approach with more preference towards judgmental and expert knowledge rather than hard data.

The researcher decided to use GTM to investigate the phenomenon (Learning under uncertainty) within real-life contexts, especially when the boundaries between phenomenon and contexts are not clear. In addition, GTM presents a single, unified, systematic method of analysis; the previous interviews' data can be kept as well as the accounted experiences, but now the data can be analysed under a new framework. According to Charmaz [36], the major strength of GTM is that it provides tools for analyzing processes that make it easier for the researcher to follow specific steps to develop the concepts, categories, hypotheses and theory. The researcher was looking for generating data about this new topic rather than evaluating or assessing something that had already been found, as previous interviews have shown.

The study followed, using the previous interviews. However, they were now used under an assumption of qualitative data type, under GTM guidelines. A second group of interviews followed an enlargement of the professional background of the interviewees, such as a Doctor, Pilot Command, Architect, Managing Director and a Psychologist Head of School's Sixth Form. The main tool that was used for collecting the core data for this set involved again unstructured open-end interviews. Despite the fact that, in this case the concepts from the earlier were used and the aim was to enlarge the scope of the initial findings, through searching for new ideas that could generate more hypotheses in the new data.

Finally another research stage consisted of a consolidation of the previous stages, constructing a grounded theory of learning under uncertainty. For this end, a third set of interviews was directed by the emerging concepts from the previous sets, involving a selection of informants. This research stage was carried out to evaluate findings and 
confirm with previous interviewees the research findings. In addition, another goal was undertaken, in order to saturate categories and validate theory.

\section{Discussion}

Learning under uncertainty is common to all interviewees and in this interpretation the researcher looked for how individuals make meaning, i.e. how they acquire the knowledge, how they structure a network of people that can help to understand what the best under the uncertain context is. This process of learning is interpreted according to the interviewees' words as being a process of learning through experience, and sensing others' needs, and being capable to answer them. The process of learning includes learning the organization's history and values, learning through disagreements and opposition, learning to observe and be prompted to decide, not delaying the reduction of uncertainty, recognising it is a continuous practice and learning. It allows constructing a new frame, a new context, to work with constraints, to speak to others, always learning, avoiding the uncertain events. All of this process is made through the use of a human approach, dialogue and interaction with social-actors in the uncertain context. Other commonalities that have been interpreted in the interviews are the use of support systems: non-human and human, pleasure, working hard and confidence.

This is in agreement with a constructivist position where every explanation person puts forward any phenomena that is a social constructed account, and not a straightforward description of reality [37].

\subsection{Framework}

Using GTM, the researcher obtains a basic type of theory [38] which classifies specific dimensions of individuals, summarizing the commonalities found in discrete observations. Design a framework or diagramming offer a concrete image of the researcher ideas. The advantage of a framework is that it provides a visual representation of categories and their relationships [36:117]. So, the main goal of this framework is to give us a vision through time and place of the learning process. This framework describes the uncertainty environment and informs what an individual learner does. Figure 1 show the conceptual framework obtained. For example, a reading for this framework is: facing a context of uncertainty, from where great chances will occur, the learner will question "why" and what he "needs" to be better informed - this is a tacit position. Through these questions he will search for information from "mechanicistic" forms (newspapers, books, the internet, asking others, brainstorming with others, doing medical analysis, market analysis, etc.). He will also search for the remaining "unknown" in order to get better informed - this is an operational position. During this process the individual is learning, capturing knowledgeable information he is reinforcing his cognitive capacities facing the uncertainty. Eventually, the learner has support help from someone (family or company). At some stage, the learner may or may not make a decision that he has enough knowledge which will have consequences and will have an impact on him as learner - impact as result from the learning under uncertainty process. 


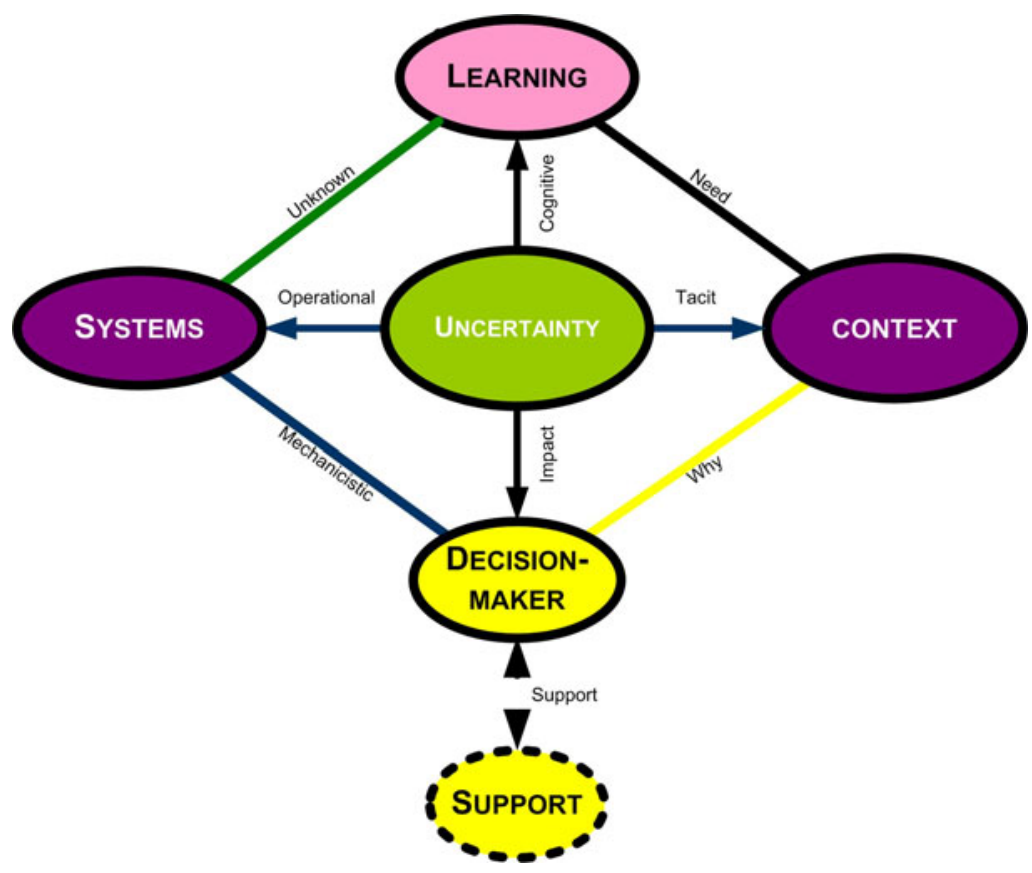

Fig. 1. Conceptual Framework derived from GTM analysis: its main goal is to give us a static vision through time and place of the learning process

The concepts shown represent:

Uncertainty The central concept that represents the unknown context, driving two axes: The horizontal represents the operational and the tacit to deal with uncertain context. The vertical is linked with the learner's cognitive, communicative and social capacities, which have an impact on him as human being.

Context The concept for the undefined reality, where uncertainty evolves and is reframed, resulting in a redefined context in order to achieve knowledge. It represents the learning goal.

Learning The concept that drives the learner to understand the context, constructing a social-web in order to understand and reframe the context.

Systems

The concept that represents the set of human techniques to build on the lack of information: scenarios, brainstorming, group meetings etc.; however it also stands for computer systems and other system devices built in order to provide factual, measured information from the defined reality.

Learner This concept represents the individual learner actor from which comes "why", the lack of information which guides the process. 
Support

A volatile concept, depending on the learner's contextual uncertain world. It could be Company (Organization) or Society (People) or even Family.

Internal links referring to the learner capacities:

Cognitive It is related with the process of knowledge construction within the social-web, created by the learner; it stands for understanding the uncertain context;

Impact It is related with the learner, the consequences of the learning under uncertainty process which may guide a decision;

Operational It relates to the information channel, from pre-defined computer systems and/or systems devices. Operational also refers to human techniques in order to get information from brainstorming, scenario building, group meetings, etc.

Tacit Refers to how the strategy to reframe the uncertain context is developed, how tacitly the uncertain context is re-constructed.

External alignments show how uncertainty is sensed:

Mechanistic Previous experiences and tools to deal with facts;

Why The personal desire to know, to understand the context;

Unknown Uncertain territory, no tools or anything at all to measure or obtain facts;

Need Call for reconstruction or re-definition of the uncertain context.

Usefulness

This conceptual framework presents the results to consider learning under uncertainty. It is the GTM methodology's outcome applied in the current research study. This conceptual framework is a constructed interpretation from the interviews analysis.

\section{Conclusion}

This paper provides an overview of the main contributions of the research and makes the ongoing task of elucidating how learners under uncertainty gain knowledge of, developing a social-web context. The researcher at first was inspecting how decisionmakers under uncertainty and complexity build a model, an external and explicit representation of part of reality as seen by the decision-maker. The results from this initial research focus in learning under uncertainty interpretation. The researcher then change for a qualitative approach, using GTM in order to study learning under uncertainty, since it is not a common subject in literature.

Furthermore, the results points of the process of learning include learning through disagreements and opposition, as well as learning to observe. It allows constructing a new frame, to work with constraints, to speak to others, always learning, avoiding the uncertain events. All of this process is made through the use of a human approach, 
dialogue and interaction with social-actors in the uncertain context. Other commonalities are the use of support systems: non-human and human, pleasure, working hard and confidence.

Finally it is presented a framework that provides a visual representation of categories and their relationships. The main points from it are the operational/tacit axis and the cognitive/impact axis.

This paper provides other researchers the opportunity to present a more complete picture of learning under uncertainty. In future, more research work is necessary to understand the influences from behavioural and organizational factors of learning under uncertainty.

\subsection{Limitations}

This research was conduced in a small set of business companies and professional activities so that the generalization of the findings to other sectors is too difficult because of different environments and context. The first limitation relates to the interviews since it is extremely demanding on research resources, therefore the researcher is obliged to rely on the experiences traces in the minds of those people who carried it out the experience of learning under uncertainty. This research proceeded on the premise that what was captured really happened, but that not all that happened was necessarily important and useful.

The second limitation is related to the results, which stands for a basic type of theory [38], although making testable predictions was not of primary concern. In addition testing is needed in order to reshape concepts and tune processes.

\section{References}

1. Checkland, P.B.: Systems Thinking, Systems Practice. Wiley, Chichester (1981)

2. Sowa, J.F., Zachman, J.A.: Extending and formalizing the framework for information systems architecture. IBM Systems Journal 31(3), 590-616 (1992)

3. Turban, E., Aronson, J.E.: Decision Support Systems and Intelligent Systems, 6th edn. Prentice Hall International, Englewood Cliffs (2001)

4. von Neumann, J., Morgenstern, O.: Theory of Games and Economic Behavior. Princeton University Press, Princeton (1944); Quoted in: Bernstein, Peter Against the gods: the remarkable story of risk. Wiley, New York, p. 269 (1996)

5. Chacko, G.K.: Decision-making under uncertainty: an applied statistics approach. Praeger (1991)

6. Biswas, T.: Decision making under uncertainty. Macmillan, Basingstoke (1997)

7. White, D.J.: Decision Theory. Aldine Transaction, New Brunswick (2006)

8. Simon, H.A.: Models of bounded rationality. MIT Press, Cambridge (1982)

9. Kahneman, D., Tversky, A.: Variants of uncertainty. In: Kahneman, Slovic, Tversky (eds.) Judgment Under Uncertainty: Heuristics and Biases, pp. 509-520. Cambridge University Press, New York (1982)

10. Thaler, R.: From Homo economicus to homo sapiens. Journal of Economics Perpectives 14, 133-141 (2000)

11. Beer, S.: The Heart of Enterprise. Wiley, Chichester (1979)

12. von Bertalanffy, L.: General System Theory: Foundations, Development, Applications. George Braziller, New York (1968) (also published 1971 by London: Allen Lane) 
13. Forrester, J.: Industrial Dynamics: a major break-through for decision-making. Harvard Business Review 36(4), 37-66 (1958)

14. Pidd, M.: Tools for Thinking - Modelling in Management Science, 2nd edn. Wiley, Chichester (2003)

15. Midgley, G.: Systemic Intervention: Philosophy, Methodology and Practice. Kluwer, New York (2000)

16. Arthur, B.W.: Complexity and Economy. Science 284, 107-109 (1999)

17. Stacey, R.D.: Strategic Management and Organisational Dynamics - The Challenge of Complexity, 4th edn. Prentice Hall Financial Times, Englewood Cliffs (2003)

18. Kurtz, C.F., Snowden, D.J.: The New Dynamics of Strategy: Sense-Making in a Complex and Complicated World. IBM Systems Journal 42(3) (2003), E-Business Management

19. Mitleton-Kelly, E. (ed.): Complex Systems \& Evolutionary Perspectives of Organisations: The Application of Complexity Theory to Organisations. Selected Papers on Complexity by 14 International Authors. Elsevier, Amsterdam (2003)

20. Steier, F.: Research and Reflexivity. Sage, Thousand Oaks (1991), Quoted in [18:9]

21. Levy, D.: Chaos theory and strategic: theory, application and managerial implications. Strategic Management Journal 15, 167-178 (1994)

22. Bernstein, P.: Against the gods: the remarkable story of risk. Wiley, New York (1996)

23. Learning Theories Knowledgebase. Index of Learning Theories and Models at LearningTheories.com (2008), http: / /www. learning-theories.com (retrieved May 26, 2008)

24. Gagne, R.M., Briggs, L.J., Wager, W.W.: Principles of instructional design. Harcourt Brace Jovanovich, Fort Worth (1992)

25. von Glasersfeld, E.: Radical constructivism: A way of knowing and learning. Falmer Press, London (1995)

26. Bligh, J.: Learning from uncertainty: a change of culture. Medical Education 35, 2 (January 2001)

27. Dayan, P., Yu, A.J.: Uncertainty and learning. IETE Journal of Research 49, 171-182 (2003)

28. Arrow, K.J.: Utilities, Attitudes and Choices: A Review Note. Econometrica, 1-23 (January 1958); Quoted in Mack, Ruth P. Planning on uncertainty: decision making in business and government administration. Wiley-Interscience, New York, p. 172 (1971)

29. Hayles, N.K.: How Became Posthuman: Virtual Bodies in Cybernetics. In: Literature and Informatics. University of Chicago Press, Chicago (1999)

30. Bryant, A.: Thinking "Informatically" A New Understanding of Informations, Communications, and Technology, p. 49. Lampeter: Edwin Mellen Press, Lewiston (2006)

31. Neuman, W.L.: Social Research Methods. Allyn and Bacon, Boston (1991)

32. Tesch, R.: Qualitative Research: Analysis Types and Software Tools. The Falmer Press, New York (1990)

33. Glaser, B.G., Strauss, A.L.: The Discovery of Grounded Theory: Strategies for Qualitative Research. Aldine Publishing Company, New York (1967)

34. Miles, M., Huberman, M.: Qualitative data analysis: A sourcebook of new methods, 2nd edn. Sage, Newbury Park (1994)

35. Eldabi, T., Irani, Z., Paul, R., Love, P.: Quantitative and Qualitative Decision Methods in Simulation Modelling. Management Decision 40(1), 64-73 (2002)

36. Charmaz, K.: Constructing Grounded Theory: A Practical Guide Through Qualitative Analysis. Sage Publications, London (2006)

37. Gergen, H.J.: The social constructionist movement in modern psychology. American Psychologist 40, 266-275 (1985)

38. Gregor, S.: The Nature of Theory in Information Systems. MIS Quarterly 30(3), 611-642 (2006) 